\title{
Plagiarism Norms and Practices in Coursework
}

\section{Assignments}

\author{
Su-Hie Ting ${ }^{1, *}$, Muriatul Khusmah Musa ${ }^{2} \&$ Florence Sau-Fong $\mathrm{Mah}^{3}$ \\ ${ }^{1}$ Centre for Language Studies, Universiti Malaysia Sarawak, 94300 Kota Samarahan, \\ Sarawak, Malaysia \\ ${ }^{2}$ Academy of Language Studies, Universiti Teknologi MARA, Pulau Pinang, Malaysia \\ ${ }^{3}$ INTI International University, Nilai, Malaysia \\ *Corresponding author: Tel: 60-82-581-781 E-mail: shting@cls.unimas.my
}

Received: December 5, 2013 Accepted: January 21, 2014 Published: February 22, 2014

doi:10.5296/ije.v6i1.4676 URL: http://dx.doi.org/10.5296/ije.v6i1.4676

\begin{abstract}
The study compared the plagiarism norms and practices among pre-university, diploma and degree students. The specific aspects examined were perceived necessity to include citations in assignments, preferred penalties for plagiarism, and academic writing practices. The questionnaire responses of 263 students from three levels of university education were analysed. The results showed that the perceived necessity for attribution in assignments is the highest for the degree students but the norm to require citations and to penalise omission of citations is not extensive at all three levels. A majority of the students felt that plagiarism should be penalised but preferred warning from their lecturer, assignment resubmission and counselling. Mosaic plagiarism is the most common whereby students combine texts from the same source or different sources without proper citation and referencing. The most common unethical help-seeking behaviour is copying another student's work. The findings suggest that while lack of knowledge on citation and referencing may lead to improper or non-attribution of sources, plagiarism cannot be dealt with by instruction on citation and referencing alone as respect for intellectual property can only be inculcated by treating plagiarism as a serious academic misdemeanour.
\end{abstract}

Keywords: plagiarism; academic writing; attribution; citation; referencing 


\section{Introduction}

University education encompasses learning ethical practices in academic writing and recognition of intellectual property through attribution. Plagiarism is "the theft of words or ideas, beyond what would normally be regarded as general knowledge" (Park, 2003, p. 472; Rezanejad \& Rezaei, 2013). An example of a definition of plagiarism presented to students is "submitting or presenting work in a course as if it were the student's own work done expressly for that particular course when, in fact, it is not" (University of Calgary, n.d.; see also Pecorari, 2010). This includes passing off ideas and words which are not the student's own work without acknowledging the source through citation and referencing. However, when students are taught citation and referencing conventions in academic writing courses, the emphasis is often on rules for the use of punctuation marks and elliptical information to show author's names, title of research article, journal or book, volume, issue and page numbers as well as publisher information (Mah \& Ting, 2013). The mechanics get more attention than respect for intellectual property of others and plagiarism as a theft of words and ideas. Students should be taught "what academic integrity involves, why professors value it, and how exactly to carry it out" (Blum, 2009, A35). The number of articles that are published on plagiarism in academic writing shows that academics and researchers are concerned about unethical practices in academic writing.

Studies have shown that prevailing norms on attribution in academic writing influence use of writing strategies that constitute plagiarism. Top-down university policies on plagiarism influence prevalence of plagiarism. For example, Sheard, Dick, Markham, Macdonald, and Walsh (2002) conducted a survey on 287 first year information technology students in two Australian universities, Monash and Swinburne, and found that the Swinburne students were more aware of plagiarism regulations at their university because of the recent crackdown on plagiarism. When students and academics who plagiarise are not penalised, this creates the environment for more unethical practices in academic writing. When the university ignores claims of plagiarism by academics and even promotes the lecturer in question without a proper investigation, it sends the message that plagiarism is acceptable (e.g., Malaysia Kini, 2013). When cheaters go unpunished, this sets up a situation which rewards cheaters and disadvantages those who maintain academic integrity (Callahan, 2006; Jones, 2014; O'Neill $\&$ Pfeiffer, 2012). Cheaters do not have to be diligent or demonstrate ability; yet they gain an unfair advantage over others through unethical means (Bloodgood, Turnley, \& Mudrack, 2008). Over time, universities which condone plagiarism develop lax norms on ethical practices in academic writing.

Besides university policies on plagiarism, the lecturers' attitudes and actions on plagiarism also create the norms on responsible academic writing because students are in direct contact with lecturers, and the lecturers implement the university policy on plagiarism, if any. For instance, a majority of the students in Ryan, Bonanno, Krass, Scouller, and Smith's (2009) study were unsure of the content of their university policy on plagiarism although they were aware of the existence of such a policy. Ryan et al.'s study was a large scale study involving 1080 students (990 undergraduate; 90 postgraduate) at the University of Sydney. They found that the students' awareness of plagiarism did not increase with more years spent at the 
university and they used a wide range of inappropriate strategies for using source materials in their academic writing but they felt that textual borrowing is acceptable. Ryan et al. concluded that the students' ideas of acceptable and unacceptable textual borrowing practices may differ from those of the research community. When students are caught for plagiarism, they often deny wrongdoing on their part (Michael, 2000) and blame their instructors for their ignorance (LoCastro \& Masuko, 1997). The different understanding on acceptable textual borrowing practices may be compounded by conflicting information given by lecturers on "boundaries between acceptable and unacceptable practices" (Flint, Clegg, \& Macdonald, 2006 , p. 152). Other researchers attribute the different understanding of plagiarism to the inconsistent and inequitable institutional policy and practices on plagiarism (Devlin, 2006; Walker, 1998). One way to detect prevailing norms on ethical academic writing in the university is by asking students whether their peers plagiarise. Scanlon and Neumann (2002) found that students tended to report higher incidence of plagiarism among their peers than themselves, and they are more likely to plagiarise if they perceive a majority of their peers doing so.

There are indications that some cultures have more permissive norms on plagiarism. So far, researchers have written about students from these countries as having ideas of intellectual property and plagiarism which may differ from that of the research community: Vietnam (Phan, 2006); Japan (LoCastro \& Masuko, 1997); China (Pennycook, 1996). These happen to be Asian countries with a collectivistic culture where group interests prevail over individual interests and, because of that, lower value is given to individual ideas than in individualistic cultures. The reasons for more permissive norms on plagiarism fall into three categories. First, different societal norms on intellectual property and attribution may make students prone to plagiarism. Phan (2006) stated that "in Vietnamese universities it is acceptable for students to give a full list of bibliography at the end of their essays without having to give full in-text references to the readings they use" (p. 78). Such academic writing norms allow students to use information from various sources without acknowledging them one by one - an academic writing practice which contravenes what is generally accepted in the Western research discourse community. Mah and Ting (2013) also stated that in examination-oriented settings such as Malaysia, it is difficult for students to understand the severity of plagiarism, especially if they had been taught to memorise model answers for public examinations. In cultures where individual work is regarded as having low social value, students may commit plagiarism because "the word 'plagiarism' may not mean much" to them (Zobel \& Hamilton, 2002, p. 25). Second, poor English proficiency is another factor causing plagiarism (LoCastro \& Masuko, 1997; Park, 2003; Pennycook, 1996). Pennycook (1996) is among those who assert that cross-cultural aspects of second language education should be considered before accusing students of textual borrowing because from his interviews with students at a university in China, he found that students sometimes used the original language because they were incapable of rewriting it in a better manner. Another study by LoCastro and Masuko (1997) on Japanese students writing theses in English revealed that they did very little of their own writing but relied on unattributed quotations and paraphrases. Park (2003) is also of the view that plagiarism is more pronounced when students have language difficulties. Third, insufficient training in academic writing leads to unintended plagiarism 
(Phan, 2006; Divan, Bowman, \& Seabourne, 2013). For example, students may think that citation is not necessary when they have paraphrased statements from articles and they may also not realise that it is important to use direct quotation marks to indicate exact words of the authors they have cited (see also Ting, 2013). If this is the main reason, then instruction on citation and referencing conventions can solve the problem.

Thus far, the studies on plagiarism in academic writing have pointed to lack of knowledge of citation and referencing conventions, lack of language proficiency and perceptions that plagiarism is not wrong as factors leading to plagiarism. Our contention is that it is because of the prevailing permissive norms on plagiarism that lack of language proficiency and training in academic writing can be "an excuse" for unethical writing practices. The study goes beyond identifying plagiarism behaviours, a topic which has been addressed by many studies, to studying the prevailing norms on attribution in academic writing from the perspective of three levels of students: pre-university, diploma, and degree. For this study, we adapted a questionnaire that had been used in Australia (Ryan et al., 2009) to survey students' plagiarism practices and attitudes towards plagiarism in Malaysia so that a direct comparison can be made on the prevalence but we added a study of prevailing norms. The findings will add to the little which has been written about students from Asian cultures being more prone to plagiarism because of the different interpretations of plagiarism and intellectual property in these cultures.

The purpose of the study was to compare the norms and practices of plagiarism among pre-university, diploma and degree students. The specific aspects examined were perceived necessity to include citations in assignments, preferred penalties for plagiarism, and academic writing practices.

\section{Method of Study}

The participants of this study were 263 students from three levels of university education in Malaysia (28 pre-university; 66 diploma; 169 degree). The pre-university students, aged 17 to 18 , were in Semester 1 of their one year matriculation programme to prepare them for majors in science. They were enrolled in the English as a Second Language Studies subject of the South Australian Matriculation programme in INTI International University, Nilai. This was the only English subject for them and at the time of the study, they had just been given a brief lecture on plagiarism. Their lecturer (the third researcher) had told them of the need to include citation and referencing in final examination essay to obtain grades above $\mathrm{B}+$ although marks were not specifically allocated for referencing.

The second group of students, between 18 and 20 years old, were studying for a Diploma in Health Sciences and Pharmacy in Universiti Teknologi MARA, a public university in Pulau Pinang. They were in Semester 2 of their first year and had completed the first English subject (Consolidating English Language Skills) and were taking their second English subject (Intermediate English). Both English subjects focused on the four language skills and grammar. They would only learn Academic Writing in English in Semester 3, and what they 
understood of plagiarism, if any, would be based on what their discipline lecturers had told them.

The third group of students was degree students from different disciplines enrolled in an Academic Reading and Writing subject at a public university in Sarawak, Universiti Malaysia Sarawak. Aged 20 to 23, they were mainly in their second year of the degree programme (37 Year One, 110 Year Two, 22 Year Three). The questionnaire was distributed in the second week of the semester, and plagiarism had been briefly mentioned to them in the context of proper conventions for citation and referencing, a unit that stretches across four weeks. A substantial proportion of marks were set aside for citation and referencing for the two coursework assignments in Academic Reading and Writing subject.

The questionnaire used to study students' awareness of plagiarism and academic writing practices was adapted from Ryan, Bonnano, Krass, Scouller, and Smith (2009). The questionnaire covered preferred penalties for plagiarism and strategies for completing written assignments. Ryan et al. (2009) examined preferred penalties for first- and second-time incidents of plagiarism but for the present study, the students were only asked to indicate whether they agreed with a list of nine actions (yes/no options). To the strategies for completing written assignments, an item on translating was included because in Malaysia, information may be available in either English or Bahasa Malaysia. In addition, a section was added to obtain information on the norms for inclusion of citation and referencing in coursework assignments, and these included knowledge of citation and referencing conventions, and lecturer's requirements on attribution and their peers' practices in inclusion of citations and references in assignments. For a detailed description of adaptations made to Ryan et al.'s questionnaire, see Musa and Ting (2013).

The questionnaires were distributed at the beginning of the semester to find out students' awareness of plagiarism and academic writing practices before they were given detailed instruction on these in their respective English subjects. In the case of the pre-university and degree students, they were enrolled in an English subject which would deal with these in depth during the semester but the diploma students would only learn this in a subsequent English subject. This situation influences the results as will be seen in the next section.

For students' responses on their preferred penalties for plagiarism and norms on citation and referencing practices in their institutions, percentages of agreement were calculated. For commonly used strategies for completing assignments, means were calculated from their Likert-type responses of 1 for never, 2 for sometimes, 3 for often, 4 for usually and 5 for always. Using percentages and means enabled comparison across the three groups of students. While the differences in participant numbers for the three groups may raise some concern, it is an inevitable situation because of the existing student numbers in the English subjects selected for the data collection. The students are from three different institutions because not all universities offer the pre-university, diploma and degree programmes; otherwise, a longitudinal study would offer insight into students' awareness and practices of plagiarism as they move up to higher levels of tertiary education. Nevertheless, the results offer some preliminary results on norms and practices of plagiarism in academic writing among students 
from three educational levels for future verification.

\section{Results and Discussion}

\subsection{Norms on citations in assignments}

The norms of academic writing were deduced from students' knowledge of citation and their perception of requirements on including citations in assignments and penalties for omitting attribution of sources.

Table 1. Percentage of students with different proportions of correctness in citation conventions

\begin{tabular}{lcccc}
\hline $\begin{array}{l}\text { Proportion of correctness in citation } \\
\text { conventions }\end{array}$ & $\begin{array}{c}\text { Pre-university } \\
(\mathrm{n}=28)\end{array}$ & $\begin{array}{c}\text { Diploma } \\
(\mathrm{n}=66)\end{array}$ & $\begin{array}{c}\text { Degree } \\
(\mathrm{n}=169)\end{array}$ & $\begin{array}{c}\text { Overall } \\
(\mathrm{n}=263)\end{array}$ \\
\hline Mostly correct & 17.9 & 13.6 & 17.8 & 16.4 \\
Half correct, half wrong & 21.4 & 25.8 & 49.1 & 32.1 \\
Mostly wrong & 3.6 & 1.5 & 8.9 & 4.7 \\
Do not know if I got it correctly or wrongly & 57.1 & 59.1 & 24.3 & 46.9 \\
\hline Total & 100 & 100 & 100.1 & 100.1 \\
\hline
\end{tabular}

* Total does not add up to 100 due to rounding off

Next, the results on students' perception of requirements on including citations in assignments show that the requirement was stricter in degree programmes than either pre-university or diploma programmes. Table 2 shows that $66.3 \%$ of the degree students reported that citations were required for all assignments compared to $35.7 \%$ of pre-university and $19.7 \%$ of diploma students. For the pre-university students in this study, the requirement to include citations in assignments varies as shown by the rather even distribution of percentages across the proportions of assignments requiring citations. The requirement to include citations in assignments was the lowest for the diploma students and highest for the degree students in this study.

Table 1 shows that less than $18 \%$ of students from pre-university, diploma and degree levels reported that their citations were mostly correct, showing inadequate knowledge of citation conventions. However, the degree students were more certain of whether they had used the correct conventions because only $24.3 \%$ of the degree students were unsure as compared to $57.1 \%$ of pre-university and $59.1 \%$ of diploma students. This indicates that the degree students in this study had better knowledge of conventions for attributing sources of information. 
Table 2. Percentage of students reporting necessity to include citations in assignments

\begin{tabular}{lcccc}
\hline $\begin{array}{l}\text { Proportion of assignments for } \\
\text { which citations are required }\end{array}$ & $\begin{array}{c}\text { Pre-university } \\
(\mathrm{n}=28)\end{array}$ & $\begin{array}{c}\text { Diploma } \\
(\mathrm{n}=66)\end{array}$ & $\begin{array}{c}\text { Degree } \\
(\mathrm{n}=169)\end{array}$ & $\begin{array}{c}\text { Overall } \\
(\mathrm{n}=263)\end{array}$ \\
\hline All & 35.7 & 19.7 & 66.3 & 40.6 \\
About three-quarters & 17.7 & 9.1 & 13.6 & 13.5 \\
About half & 21.4 & 34.8 & 11.2 & 22.5 \\
About one-third & 14.3 & 28.8 & 6.5 & 16.5 \\
None & 10.7 & 7.6 & 2.4 & 6.9 \\
\hline Total & 100 & 100 & 100 & 100 \\
\hline
\end{tabular}

If inclusion of citations in assignments is a requirement but this is not backed up by enforcement in the form of penalties such as mark deductions, the requirement may not carry weight. It seems that the penalty for non-attribution of sources in assignments is the most prevalent for the degree students and the least prevalent for the diploma students in this study. Table 3 shows that more degree students reported that marks were always deducted for omission of citations: $21.9 \%$ degree students, $10.7 \%$ of pre-university students and $1.5 \%$ of diploma students.

The same conclusion is reached by taking the percentage of students who reported that marks were never or sometimes deducted if they did not include citations (67.9\% for pre-university; $90.9 \%$ for diploma; $56.8 \%$ for degree). The earlier results reported in Table 2 also shows that the requirement to include citations in assignments was the lowest for the diploma students and the highest for the degree students in this study.

Table 3. Percentage of students reporting mark deductions for citation omissions

\begin{tabular}{lcccc}
\hline Frequency of mark deduction & $\begin{array}{c}\text { Pre-university } \\
(\mathrm{n}=28)\end{array}$ & $\begin{array}{c}\text { Diploma } \\
(\mathrm{n}=66)\end{array}$ & $\begin{array}{c}\text { Degree } \\
(\mathrm{n}=169)\end{array}$ & $\begin{array}{c}\text { Overall } \\
(\mathrm{n}=263)\end{array}$ \\
\hline Always & 10.7 & 1.5 & 21.9 & 11.4 \\
Most of the time & 21.4 & 7.6 & 21.3 & 16.8 \\
Sometimes & 17.9 & 60.6 & 45.6 & 41.4 \\
Never & 50.0 & 30.3 & 11.2 & 30.5 \\
\hline Total & 100 & 100 & 100 & 100.1 \\
\hline
\end{tabular}

* Total does not add up to 100 due to rounding off

This study shows that lecturers' requirement on inclusion of citations in assignments sets the norm for responsible attribution in academic writing. The earlier results are confirmed by another set of results on students' reasons for omitting citations (Table 4). For this item in the questionnaire, students were allowed to tick more than one response; hence, total percentages for each group of students were not calculated as they exceeded $100 \%$. 
Table 4. Percentage of students choosing various reasons for omitting citations in assignments

\begin{tabular}{lcccc}
\hline Reasons for omitting citations in assignments & $\begin{array}{c}\text { Pre-university } \\
(\mathrm{n}=28)\end{array}$ & $\begin{array}{c}\text { Diploma } \\
(\mathrm{n}=66)\end{array}$ & $\begin{array}{c}\text { Degree } \\
(\mathrm{n}=169)\end{array}$ & $\begin{array}{c}\text { Overall } \\
(\mathrm{n}=263)\end{array}$ \\
\hline I don't know how to cite & 53.6 & 63.6 & 65.7 & 61.0 \\
My lecturers didn't ask me to cite & 32.1 & 51.5 & 38.5 & 40.7 \\
My lecturers don't minus marks if we don't & 25.0 & 43.9 & 20.7 & 29.9 \\
cite & & & & \\
I want lecturers to think the ideas are mine & 28.6 & 9.1 & 12.4 & 16.7 \\
My friends also didn't cite & 7.1 & 40.9 & 17.2 & 21.7 \\
\hline
\end{tabular}

Although a majority of students gave lack of knowledge as the main reason for omitting citations in assignments, the main deterrent for not doing so is their lecturers' expectations on ethical academic writing practices. Table 4 shows that if the percentages for lecturers not requiring citations and lecturers not penalising them for citation omission are added together, this confirms the results reported in Tables 2 and 3. If lecturers are lax as in the diploma programme $(95.4 \%)$ and stricter as in the degree $(59.2 \%)$ and pre-university programmes $(57.1 \%)$, this indirectly set the norms on attribution in academic writing. Whether the lecturers are conscious of their actions or not, the students are quick in picking it up - as shown by the relatively high percentage of diploma students $(40.9 \%)$ saying that they omitted citations in assignments because their friends were doing so and the much lower percentages for the other two groups of students (7.1\% pre-university students; $17.2 \%$ degree students). If the requirement for including citations is made explicit and lecturers show that they are serious about it, students will find ways to learn citation conventions from their lecturers, the Internet, friends and books.

A possible explanation for the apparently more relaxed norms on attribution for the diploma students is the type of coursework assignments. Most of the assignments for the Health Sciences and Pharmacy diploma students are laboratory reports which do not require citations. The emphasis is on acquiring laboratory skills, reporting observations and drawing conclusions based on the observations. It is only in the third English subject (Academic Writing) that the lecturers require citations to substantiate ideas and the lecturers are strict about plagiarism. The other lecturers who give coursework assignments that require students to get information from other sources (e.g., a report on diseases) were more concerned about student's ability to search for information, particularly for students in the first year of their 3-year diploma programme. They accept the students' assignments even though the students do not acknowledge the sources, or cut and paste information from various sources. They would only take plagiarism seriously when checking the students' final year research project report. By this time, plagiarism would have become a habit and it would not be easy for the students to suddenly take attribution seriously. 


\subsection{Students' choice of penalties for plagiarism}

The three most preferred penalties for plagiarism are receiving a warning from the lecturer, resubmitting the assignment and receiving counselling (Table 5). All three do not carry permanent negative consequences on the students as the verbal warning and counselling do not affect their marks in the assignment or the course. Neither does resubmission of the assignment; in fact, this gives them a second chance to do well in the assignment. There is no difference across the three groups of students on the three most preferred penalties for plagiarism.

Table 5. Students' choice of penalties for plagiarism

\begin{tabular}{lcccc}
\hline Penalties for plagiarism & $\begin{array}{c}\text { Pre-university } \\
(\mathrm{n}=28)\end{array}$ & $\begin{array}{c}\text { Diploma } \\
(\mathrm{n}=66)\end{array}$ & $\begin{array}{c}\text { Degree } \\
(\mathrm{n}=169)\end{array}$ & $\begin{array}{c}\text { Overall } \\
(\mathrm{n}=263)\end{array}$ \\
\hline $\begin{array}{l}\text { 1. Student receives a warning from the } \\
\text { lecturer }\end{array}$ & 82.1 & 87.9 & 89.9 & 86.6 \\
2. Student is asked to resubmit the & 85.7 & 81.8 & 88.2 & 85.2 \\
$\quad$ assignment & & & & \\
3. Student receives counselling & 69.9 & 80.3 & 81.1 & 77.1 \\
4. The incident is reported to the faculty & 35.7 & 45.4 & 59.2 & 46.8 \\
5. Student gets an "F" (fail) for the & 21.4 & 22.7 & 37.9 & 27.3 \\
assignment & & & & \\
6. The incident is reported to the university & 17.9 & 22.7 & 40.8 & 27.1 \\
7. No action taken & 25.0 & 24.2 & 13.6 & 20.9 \\
8. Student gets an "F" (fail) for the course & 10.7 & 6.1 & 24.3 & 13.7 \\
9. Student is expelled from the university & 7.1 & 4.5 & 11.8 & 7.8 \\
\hline
\end{tabular}

*Students could tick more than one type of penalty

The penalty which about half of the students favour is having the plagiarism incident reported to the faculty. This is more serious than a warning from the lecturer, counselling or assignment resubmission as it could mean disciplinary action. The students did not like disciplinary action of any kind, for example, failing the assignment, failing the course, having the incident reported to the university, and being expelled from the university. Similar results were found by Ryan et al. (2009) on students not preferring disciplinary action involving students failing the assignment or course or expulsion but in their study, only half of the students agreed to resubmitting the assignment or undertaking another form of assessment.

Another result which deserves attention is the percentage of students who preferred no action to be taken for plagiarism cases. Less than one-quarter of 236 students chose this response, indicating that the majority felt that plagiarism should be penalised in some way but not in ways that hurt them in their marks, grade or status in the university. To them, plagiarism is "no big deal" (Ting, 2013). 


\subsection{Unethical help-seeking behaviours}

Based on the students' reports, they seldom sought help to complete assignments unethically as the mean frequencies generally ranged between 1 (never) and 3 (often). Since there is some variation in the results across the three student groups, the results will be described separately for the groups (see Table 6).

For the pre-university students, the most common plagiarism behaviour is getting somebody to fix up the assignments to make it better but this only took place some of the time (mean of 2.03, Table 6). Other plagiarism behaviours that they admitted to committing some of the time are copying other students' work with their knowledge and including Internet materials in assignments without referencing. The diploma students reported slightly more frequent plagiarism behaviours as indicated by more items with means between 2 and 3 but the more frequent plagiarism behaviours are similar to the pre-university students. In addition to these, they also admitted to submitting an assignment which had already been given marks. Since similar assignment questions may be given to students from different cohorts, students can submit their seniors' assignments as their own. The student community within a particular diploma programme is close-knit and the seniors may help the juniors in this manner, and this also happens for the degree students in this study. While the degree students are less likely to get others to fix up their assignments in order to make them better, they went further to get somebody else to write the whole or part of their assignments. This is worse because they are submitting work that is not their own.

Table 6. Mean frequency of plagiarism behaviours

\begin{tabular}{|c|c|c|c|c|}
\hline Plagiarism behaviours & $\begin{array}{l}\text { Pre-university } \\
\qquad(\mathrm{n}=28)\end{array}$ & $\begin{array}{l}\text { Diploma } \\
(\mathrm{n}=66)\end{array}$ & $\begin{array}{l}\text { Degree } \\
(n=169)\end{array}$ & $\begin{array}{l}\text { Overall } \\
(\mathrm{n}=263)\end{array}$ \\
\hline $\begin{array}{l}\text { 1. Copying another student's work with } \\
\text { his/her knowledge. }\end{array}$ & 1.85 & 2.79 & 2.72 & 2.45 \\
\hline $\begin{array}{l}\text { 2. Downloading material from the Web } \\
\text { and including it in their assignments } \\
\text { without referencing }\end{array}$ & 1.96 & 2.21 & 2.94 & 2.37 \\
\hline $\begin{array}{l}\text { 3. Getting somebody to fix up their } \\
\text { assignments in order to make it better. }\end{array}$ & 2.03 & 2.17 & 2.01 & 2.07 \\
\hline $\begin{array}{l}\text { 4. Submitting an assignment that has } \\
\text { already been given marks. }\end{array}$ & 1.07 & 2.24 & 2.41 & 1.91 \\
\hline $\begin{array}{l}\text { 5. Getting somebody else to write their } \\
\text { assignments/part of their assignments. }\end{array}$ & 1.17 & 1.41 & 2.43 & 1.67 \\
\hline $\begin{array}{l}\text { 6. Copying another student's work } \\
\text { without his/her knowledge. }\end{array}$ & 1.14 & 1.32 & 2.30 & 1.59 \\
\hline
\end{tabular}

Note: $1=$ Never; $2=$ Sometimes; $3=$ Often, 4=Usually; 5=Always

When the mean frequencies of the three groups of students are compared, it seems that the range of frequent plagiarism behaviours increases from pre-university to diploma and peaks at the degree level. This is not a good sign where ethical academic writing practices are concerned and suggests that the need to enforce penalties on plagiarism is probably higher in 
degree programmes where students may be required to produce more assignments with citations and references. The results for this study are based on a survey conducted at the beginning of an academic writing course. A post-survey of the same group of degree students conducted after one semester of learning academic writing showed that greater use of unethical help-seeking strategies (for full report, see Law, Ting, \& Jerome, 2013). Whether the use of unethical help-seeking behaviour would increase from the time the students entered university to the time they leave university remains to be investigated in future studies.

\subsection{Plagiarism in writing assignments}

Table 7. Mean frequency for strategies to handle citations and references

\begin{tabular}{lcccc}
\hline Strategies to handle citations and references & $\begin{array}{c}\text { Pre-university } \\
(\mathrm{n}=28)\end{array}$ & $\begin{array}{c}\text { Diploma } \\
(\mathrm{n}=66)\end{array}$ & $\begin{array}{c}\text { Degree } \\
(\mathrm{n}=169)\end{array}$ & $\begin{array}{c}\text { Overall } \\
(\mathrm{n}=263)\end{array}$ \\
\hline $\begin{array}{l}\text { 1. I write a paragraph by taking a few } \\
\text { words from a few articles and put them }\end{array}$ & 3.53 & 3.42 & 3.35 & 3.43 \\
together. I add my own words to make \\
the meaning clear and include the \\
$\quad$ source in the reference list.
\end{tabular}

Note: $1=$ Never; $2=$ Sometimes; $3=$ Often, 4=Usually; 5=Always

*Not plagiarism behaviour 
Table 7 focusses on plagiarism behaviours that are specific to strategies in handling citations and references. As a benchmark for comparison, Items 2 and 4 in Table 7 showing correct citation and referencing conventions in writing are included. Item 2 which deals with paraphrasing has the second highest overall mean frequency of 2.88. Item 4 which deals with direct quotations has the fourth highest overall mean frequency of 2.56. This is a good indication in that correct citation and referencing practices is often practised by the students, more at degree level than at diploma or pre-university level. It is important to recognise the difference between paraphrasing and direct quotation because passing off somebody's words as one's own is plagiarism. Even though such plagiarism can be avoided by using direct quotation marks to indicate the source of the words, this simple convention seems to be forgotten. Wilhoit (1994) makes it very clear that if direct quotations are used without the quotation marks with attribution, the source of the language to explain the ideas has not been acknowledged.

The two most common strategies to complete written assignments which constitute plagiarism are combining information from the same or different articles to form paragraphs. The most frequent strategy adopted by the three groups of students is writing a paragraph by putting together words from a few articles and including the source in the reference list (overall mean frequency of 3.43 which is between "often" and "usually"), and this is unethical. The second most frequent plagiarism behaviour is using reordering sentences from one source but the source is cited and included in the reference list (overall mean frequency of 2.75). In this case, the students rely on only one source. The problem is these sentences are usually not presented as direct quotations with proper attribution for each of them. Very often, only one sentence is marked as originating from the source whereas the rest are passed off as the students' own writing. These two plagiarism behaviours are referred to as "mosaic plagiarism". The American Medical Association Manual of Style describes mosaic plagiarism as:

borrowing the ideas and opinions from an original source and a few verbatim words or phrases without crediting the original author. In this case, the plagiarist intertwines his or her own ideas and opinions with those of the original author, creating a confused, plagiarized mass. (Iverson, Flanagin, Fontanarosa, Glass, Glitman, \& Lantz, 1998, p. 104)

When students' proficiency in English is inadequate, the tendency to resort to mosaic plagiarism is higher because to paraphrase, students need to first understand the article and then write it in their words. When the subjects are taught in English, the coursework assignments must be written in English. Since most students are not proficient in English, they are not able to paraphrase the ideas correctly or do not know how to express the ideas in English, and plagiarism is an easy way out.

The last four items in Table 7 show even worse plagiarism behaviours in attribution of source because the source is not cited: copying a sentence from an article; cutting and pasting information from the Internet; inventing references; and translating from another language. The overall mean frequencies are $2.55,2.48,2.45$ and 2.35 respectively (Table 7), which 
places the frequency of these plagiarism behaviours between "sometimes" and "often". This is blatant stealing of ideas because the source of the ideas is not acknowledged. The results show that the students admitted to committing plagiarism of both printed and online sources. Research has yielded mixed results with some showing that online sources were more likely to be plagiarised (see Auer \& Krupar, 2001; Scanlon, 2003) whereas others showed that printed and electronic versions of source texts were equally likely to be plagiarised (Bilić-Zulle, Frkovic, Turk, Azman, \& Petrovecki, 2005). Bilić-Zulle et al.'s (2005) study involved 198 medical students in a university in Croatia. It is common for students to use materials from the Web without proper referencing in essays (Lyon, Barrett, \& Malcolm, 2006) but digital natives do not necessarily cheat more than non-natives in information communication technology (Byrne, 2013). Naturally it is easier for students to plagiarise online sources because of the ease of cutting and pasting texts. Furthermore, there are many assignments posted by other students for similar assignment topics, for example, the diploma students in this study were asked to discuss general issues like pollution and online shopping. Plagiarism is an easy way out compared to the arduous task of writing topic sentences and substantiating these with details along a certain theme.

A comparison of means for the three groups of students on the six items constituting plagiarism behaviours in writing (Items $1,3,5,6,7,8)$ showed that the incidence increased from pre-university (2.44) and diploma (2.64) to degree (2.93). It seems that the higher the educational level, the more prone the students are to plagiarism when completing written assignments. It is possible that in degree programmes, most of the assignments require reference to other sources of information and, therefore, the need to plagiarise is greater. It is not due to more relaxed norms on plagiarism in the university because a larger proportion of degree students reported the need to include citations in assignments, the incidence of mark deduction for omission of citations and the likelihood of their peers committing plagiarism than either pre-university or diploma levels. In fact, the norms are the most permissive for the diploma students. Results on inadequate knowledge of citation and referencing conventions are similar for the three groups of students. For the degree students, a post-survey conducted at the end of the semester showed reduced use of plagiarism to complete assignments but increased reports of help-seeking strategies (e.g., copying, submitting previously marked assignments, getting others to write whole or part of assignment) (for full report, see Law, Ting, \& Jerome, 2013). While instruction in academic writing can minimise plagiarism in writing strategies by addressing lack of knowledge on attribution, it cannot address unethical help-seeking strategies which may flourish in universities with lax attitudes towards plagiarism.

What has been examined in this study are the norms created by individual lecturers through requirements for attribution and mark deduction for omission of attribution but these are small-scale norms restricted to the particular subject. What was not examined in this study is the university-wide norm set by enforcement of university policies on plagiarism (if any). Academics and students would take plagiarism seriously if there are severe penalties. Otherwise, plagiarism is an easy way out in academic writing. So far, marks are specifically allocated for citation and referencing for certain English courses in the three universities 
studied, which means that plagiarism is officially recognised as an unacceptable act by the language faculties. Other faculties may be more permissive in that they usually treat only plagiarism in final year research reports seriously. It is not easy for lecturers to fail students on account of plagiarism because this disciplinary action would have to result from different levels of meeting at the department, faculty and the university. The procedures for handling of plagiarism cases are usually long drawn and unwieldy (e.g., students would have to sign documents to admit that they have committed plagiarism and they can refuse to do so). The university is also sometimes very concerned that the fail grade would result in repeats of the subject and a delay in graduation for the student. Under such circumstances, plagiarism cases are usually settled unofficially by means of a warning, assignment resubmission and some mark deduction for the assignment but not amounting to a fail for the subject. The alternative to enforcing penalties for plagiarism is deterring plagiarism. Some faculties are beginning to implement plagiarism detection through Turnitin whereby students are asked to upload their assignments to a special website which will show the percentage of plagiarism but currently, it is done on a limited scale for industrial training report, final year research project and some assignments. Plagiarism detection measures such as Turnitin can make students less inclined to plagiarise (Graham-Matheson \& Starr, 2013; Heckler, Rice, \& Ryan, 2013). Some students do not mind plagiarism detection and these are probably those who do not commit plagiarism (e.g., Dahl, 2007). The best combination in addressing plagiarism is instruction in academic writing, and setting in place deterrents and penalties for plagiarism at the university level to create norms that support ethical academic writing.

\section{Conclusion}

The study showed that the students often plagiarise when they write their coursework assignments but they felt that they should only be penalised with a warning from their lecturer, assignment resubmission and counselling if they are caught for plagiarism. The plagiarism may be attributed to lack of knowledge of citations and referencing conventions and the most common form of plagiarism is mosaic plagiarism where they combine texts from the same or different sources without attribution. This study also shows that plagiarism is probably encouraged by lack of concerted effort on the part of lecturers to require attribution for assignments and deduct marks for omission of attribution. The findings suggest that students need to learn not only citations and referencing conventions but also respect for intellectual property, and the universities need to work at creating norms that support ethical academic writing. 


\section{References}

Auer, N. J., \& Krupar, E. M. (2001). Mouse click plagiarism: The role of technology in plagiarism and the librarian's role in combating it. Library Trends, 49(3), 415-432.

Bilić-Zulle, L., Frkovic, V., Turk, T., Azman, J., \& Petrovecki, M. (2005). Prevalence of plagiarism among medical students. Croatia Medical Journal, 46(1), 126-131.

Bloodgood, J. M., Turnley, W. H., \& Mudrack, P. (2008). The influence of ethics instruction, religiosity and intelligence on cheating behavior. Journal of Business Ethics, 82, 557-571. http://dx.doi.org/10.1007/s10551-007-9576-0

Blum, S. D. (2009). Academic integrity and student plagiarism: A question of education, not ethics. The Chronicle of Higher Education, 55(24), A35. Retrieved January 17, 2014, from http://www.jfdp.org/forum/forum_docs/1013jfdp1239_1_032212141103.pdf

Byrne, K. (2013). Education undergraduates and ICT-enhanced academic dishonesty: A moral panic? Education students and ICT-enhanced dishonesty. British Journal of Educational Technology, 44(1), 6-19. http://dx.doi.org/10.1111/j.1467-8535.2012.01381.x

Callahan, D. (2006). On campus: Author discusses the "cheating culture" with college students. Plagiary: Cross-disciplinary studies in plagiarism, fabrication, and falsification, 25-32.

Dahl, S. (2007). Turnitin: The student perspective on using plagiarism detection software. Active Learning in Higher Education, 8(2), 173-191. http://dx.doi.org/10.1177/1469787407074110

Devlin, M. (2006). Policy, preparation and prevention: Proactive minimisation of student plagiarism. Journal of Higher Education Policy and Management, 28(1), 45-58. http://dx.doi.org/10.1080/13600800500283791

Divan, A., Bowman, M., \& Seabourne, A. (2013). Reducing unintentional plagiarism amongst international students in the biological sciences: An embedded academic writing development programme. Journal of Further and Higher Education, (ahead-of-print), 1-21. http://dx.doi.org/10.1080/0309877X.2013.858674

Flint, A., Clegg, S., \& Macdonald, R. (2006). Exploring staff perceptions of student plagiarism. Journal of Further and Higher Education, 30(2), 145-156. http://dx.doi.org/10.1080/03098770600617562

Heckler, N, C., Rice, M., \& Bryan, C. H. (2013). Turnitin systems: A deterrent to plagiarism in college classrooms. Journal of Research on Technology in Education, 45(3), 229-248.

Iverson C., Flanagin A., Fontanarosa P. B., Glass, R. M., Glitman, P., \& Lantz, J. C., et al. (1998). American Medical Association Manual of Style: A guide for authors and editors (9th ed.). Philadelphia: Williams and Wilkins.

Graham-Matheson, L., \& Starr, S. (2013). Is it cheating - or learning the craft of writing? Using Turnitin to help students avoid plagiarism. Research in Learning Technology, 21, 
17218, 1-13. http://dx.doi.org/10.3402/rlt.v21i0.17218

Jones, J. C. (2014). What's in it for me? An examination of accounting students' likelihood to report faculty misconduct. Journal of Business Ethics. http://dx.doi.org/10.1007/s10551-013-2015-5

Law, L., Ting, S. H., \& Jerome, C. (2013, Aug 27-30). Cognitive dissonance in dealing with plagiarism in academic writing. Proceedings of 9th International Conference on Cognitive Science, Kuching, Malaysia.

LoCastro, V., \& Masuko, M. (1997, March 11-15). Plagiarism and academic writing of NNS learners. Paper presented at the Annual meeting of the Teachers of English to Speakers of Other Languages, Orlando, Florida. ED409724.

Lyon, C., Barrett, R., \& Malcolm, J. (2006). Plagiarism is easy, but also easy to detect. Plagiary: Cross-disciplinary studies in plagiarism, fabrication, and falsification, 57-65.

Mah, F., \& Ting, S. H. (2013, June 28-29). Academic literacy: Plagiarism in pre-university students' academic writing. Paper presented at International Conference on Learning and Teaching 2013, Shah Alam, Selangor, Malaysia

Malaysia Kini. (2013, November 21). Come and face me, Ridhuan Tee tells critics over plagiarism allegations. Retrieved December 4, 2013, from http://www.themalaysianinsider.com/malaysia/article/come-and-face-me-ridhuan-tee-tel ls-critics-over-plagiarism-allegations

Michael, B. (2000). Busting the new breed of plagiarist. Writer's Chronicle. Retrieved March 18, 2013, from http://awpwriter.org/magazine/writers/bugeja1.htm

Musa, M. K., \& Ting, S. H. (2013, May 29-31). Plagiarism in students' academic writing: Common practices. Proceedings of International Conference on Languages, UPALS, Pulau Pinang, Malaysia.

O'Neill, H. M., \& Pfeiffer, C. A. (2012). The impact of honour codes and perceptions of cheating on academic cheating behaviours, especially for MBA bound undergraduates. Accounting Education, 21(3), 231-245.

Park, C. (2003). In other (people's) words: Plagiarism by university students - literature and lessons. Assessment \& Evaluation in Higher Education, 28(5), 471-488. http://dx.doi.org/10.1080/02602930301677

Pecorari, D. (2010). Academic writing and plagiarism: A linguistic analysis. London, United Kingdom: Continuum International Publishing Group.

Pennycook, A. (1996). Borrowing other's words: Text, ownership, memory, and plagiarism. TESOL Quarterly, 30(2), 201-230. http://dx.doi.org/10.2307/3588141

Phan, L. H. (2006). Plagiarism and overseas students: stereotypes again? ELT Journal, 60(1), 76-78. http://dx.doi.org/10.1093/elt/cci085 
Rezanejad, A., \& Rezaei, S. (2013). Academic dishonesty at universities: The case of plagiarism among Iranian language students. Journal of Academic Ethics, 11(4), 275-295. http://dx.doi.org/10.1007/s10805-013-9193-8

Ryan, G., Bonanno, H., Krass, I., Scouller, K., \& Smith, L. (2009). Undergraduate and postgraduate pharmacy students' perceptions of plagiarism and academic honesty. American Journal of Pharmaceutical Education, 73(6), 1-8.

Scanlon, P. M. (2003). Student online plagiarism. College Teaching, 51(4), 161-165. http://dx.doi.org/10.1080/87567550309596432

Scanlon, P. M., \& Neumann, D. R. (2002). Internet plagiarism among college students. Journal of College Student Development, 43, 374-385.

Sheard, J., Dick, M., Markham, S., Macdonald, I. D. H., \& Walsh, M.E. (2002, June 24-26). Cheating and plagiarism: Perceptions and practice of 1st Year IT Students. Paper presented at ITiCSE conference 2002, Aarhus, Denmark. Retrieved http://delivery.acm.org/10.1145/550000/544468/p183-sheard.pdf?ip=49.50.236.235\&ac $\mathrm{c}=$ ACTIVE $\% 20$ SERVICE $\&$ CFID $=288236601 \&$ CFTOKEN $=25838760 \& \_\mathrm{acm} \_=136$ 2476627_c9da2b0b1e7d8edee220414ec63487f7

Ting, S. H. (2013, June 4-5). Academic writing: Citation is troublesome and plagiarism is no big deal. Proceedings of International Conference on Social Science Research, Pulau Pinang, Malaysia.

Walker, J. (1998). Student plagiarism in universities: What are we doing about it? Higher Education Research \& Development, 17(1), 89-106. http://dx.doi.org/10.1080/0729436980170105

Wilhoit, S. (1994). Helping students avoid plagiarism. College Teaching, 42(4), 161-164.

University of Calgary (n.d.). Retrieved November 18, 2013, from http://www.ucalgary.ca/pubs/calendar/current/k-2.html

Zobel, J., \& Hamilton, M. (2002). Managing student plagiarism in large academic departments. Australian Universities Review, 45(1), 23-30.

\section{Copyright Disclaimer}

Copyright reserved by the author(s).

This article is an open-access article distributed under the terms and conditions of the Creative Commons Attribution license (http://creativecommons.org/licenses/by/3.0/). 